\title{
Nephrotoxic Effect of Amphotericin B Administered in Different Doses and Infusion Mode in Dogs
}

\author{
E. CEYLAN ${ }^{1 *}$, H. A. AKKAN ${ }^{1}$, M. TUTUNCU ${ }^{1}$, Z. AGAOGLU $^{1}$ \\ ${ }^{1}$ Department of Internal Medicine, Faculty of Veterinary Medicine, \\ ${ }^{2}$ Yuzuncu Yil University, Van, Turkey
}

Received June 20, 2002

Accepted March 25, 2003

\begin{abstract}
Ceylan, E., Akkan, H. A., Tutuncu, M., Z. Agaoglu: Nephrotoxic Effect of Amphotericin $B$ Administered in Different Doses and Infusion Mode in Dogs. Acta Vet. Brno 2003, 72: 229-234.

In this study, nephrotoxic effect of Amphotericin B (AmB) was investigated together with clinical, biochemical, and histopathological findings in dogs intoxicated with different doses and methods of administration. 18 healthy cross-bred dogs were allocated to three groups. Amphotericin B diluted with sterile water was used. Dogs in group A $(n=6)$ were treated with 0.5 $\mathrm{mg} / \mathrm{kg} \mathrm{AmB}$ in $25 \mathrm{ml} 5 \%$ dextrose as a rapid bolus $(4-5 \mathrm{~min})$. Dogs in group B $(\mathrm{n}=6)$ were treated with $1 \mathrm{mg} / \mathrm{kg} \mathrm{AmB}$ in $50 \mathrm{ml} \mathrm{5 \%}$ dextrose as a rapid bolus (4-5 min). Dogs in group $\mathrm{C}(\mathrm{n}=6)$ were treated with $2 \mathrm{mg} / \mathrm{kg} \mathrm{AmB}$ in $1000 \mathrm{ml} \mathrm{5 \%}$ dextrose as a slow infusion (4-5 h). Clinical, haematological and biochemical analyses were made in all dogs before the experiment as well as on the $5^{\text {th }}$ and $12^{\text {th }}$ days. Haematological and biochemical values recorded before the experiment were compared with those on the $5^{\text {th }}$ and $12^{\text {th }}$ day.

After the third day of the experiment, vomiting, diarrhoea, anorexia, fever, phlebitis, irritability and tachycardia were recorded in all dogs (Groups A, B and C). However, the symptoms recognised were minimum in Group C, moderate in Group A and severe in Group B. There were differences in biochemical values among groups $(p<0.001)$. Group B was different from Group A and C in haematological parameters $(p<0.05)$. The most severe histopathologic changes were observed in Group B animals. These results suggest that the toxicity of AmB on kidney could be decreased when it is administered in a long period and more diluted form.
\end{abstract}

Amphotericin B, nephrotoxicity, haematology, biochemistry, dog

Systemic mycotic infections in dogs and cats are common and are difficult to treat successfully (Rand all et al. 1996). Since its discovery in 1953, Amphotericin B (AmB) has remained the drug of choice for the treatment of serious systemic fungal infections (Graybill and Craven 1983). AmB is a polyene antibiotic produced by Streptomyces nodosus, an actinomycete which was isolated from a soil sample obtained at Tembladora on the Orinoco River in Venezuela by Gold et al. (1956). It is a potent intravenous antifungal agent for treatment of blastomycosis, histoplasmosis, cryptococcosis, coccidiomycosis, candidiasis, torulopsis, aspergillosis, mucormycosis and has limited activity against the protozoa, Leishmaniosis and Naegleriosis (Gale 1984; Brajtburg et al. 1990; Bennett 1991; Andriole 2000; Yardley and Croft 2000). The drug has no antibacterial activity (Bennett 1991).

The antifungal activity of $\mathrm{AmB}$ is dependent on the drugs binding to cell membrane sterols. AmB binds more avidly to ergosterol, the principal sterol in fungal membranes. By binding to ergosterol, AmB causes pores or channels to form in the fungal cell membrane, allowing leakage of a variety of small molecules with eventual cell death (Lampen 1969; Gale 1984; Yu et al. 1998).

Elimination of the drug occurs primarily through renal route. In dogs and cats as in humans, the most common and dose-limiting side effect of AmB is severe nephrotoxicosis (Perfect et al. 1991; Carlson and Condon 1994; Randall et al. 1996; Bekersky et 


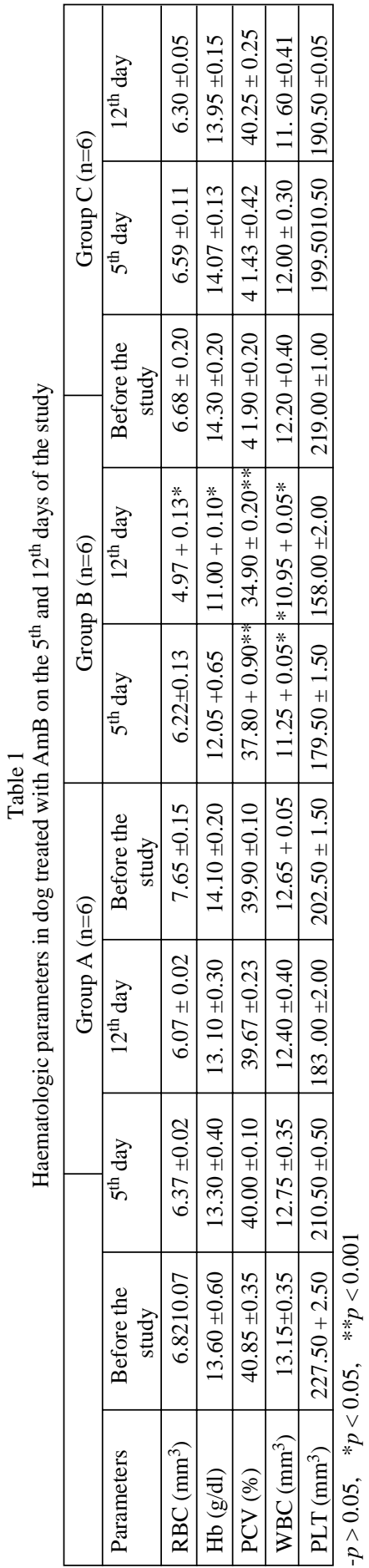

al. 2000). AmB treatment frequently must be discontinued because of development of nephrotoxicosis, thereby preventing administration of a full therapeutic dose of the drug (Maddux and Barriere 1980; Denning and Stevens 1990; Randall et al. 1996; Bekersky et al. 1999). The mechanisms responsible for $\mathrm{AmB}$ nephrotoxicity remain incompletely understood, but clearly involve reduction in renal blood flow and glomerular filtration rate (S a bra et al. 2001; Monteiro et al. 1993). Other important effect of $A m B$ is on renal tubules which were proved histopathologically (Rubin et al. 1989; B ennett 1991; Bekersky et al. 1999). Multiple approaches have been considered for reduction of nephrotoxicity of AmB. These include saline loading, simultaneous treatment with furosemide, aminophylline, mannitol, or fenoldopam, incorporation of AmB into liposomes and administration of $\mathrm{AmB}$ in $5 \%$ dextrose solutions (Gerkins and Branch 1980; Gerkins et al., 1983; Arning and Scharf 1989; Joly et al. 1989; Rubin et al. 1989; Nichols et al. 1992; Oliva et al. 1995; Randall et al. 1996, Bekersky et al. 1999; Bekersky et al. 2000). The aim of this study was to investigate the toxic effects of $\mathrm{AmB}$ in different concentrations and doses at different infusion times.

\section{Materials and Methods}

This study was approved by the Ethics Committee of Yuzuncu Yil University, Faculty of Medicine.

In this study, 18 healthy cross-bred dogs aged between 1 to 3 years and weighing 8-20 kg were allocated into three groups $(n=6)$. AmB was given and in rapid infusion in Group A and B, and slow infusion manner in Group C. Animals were housed in individual cages in temperature and humidity controlled rooms, fed daily, and allowed free access to water throughout the study. Animals were acclimatized for two weeks prior to study, and were determined to be healthy on the basis of physical examination, complete blood count (CBC), serum biochemical profile, and urinalysis.

Amphotericin B (Fungizone, SQUIBB, USA) was reconstituted with sterile water immediately prior to administration. This solution was diluted with $5 \%$ dextrose solution. AmB was given to dogs during six alternate days. Dogs in group A $(n=6)$ were treated with $0.5 \mathrm{mg} / \mathrm{kg} \mathrm{AmB}$ in $25 \mathrm{ml} \mathrm{5 \%}$ dextrose as a rapid bolus (4-5 min). Dogs in group B ( $\mathrm{n}=$ 6) were treated with $1 \mathrm{mg} / \mathrm{kg} \mathrm{AmB}$ in $50 \mathrm{ml} 5 \%$ dextrose as a rapid bolus (4-5 min). Dogs in group C $(\mathrm{n}=6)$ were treated with $2 \mathrm{mg} / \mathrm{kg} \mathrm{AmB}$ in $1000 \mathrm{ml} \mathrm{5 \%}$ dextrose as a slow infusion (4-5 h).

The dogs were observed several times a day for signs of intoxication. Body weigths were recorded before the study and on each treatment day.

Blood samples for sodium $(\mathrm{Na})$, potassium $(\mathrm{K})$, chloride $(\mathrm{Cl})$, calcium $(\mathrm{Ca})$, albumin, protein, blood urea-nitrogen (BUN), creatinin and red blood cell (RBC), haemoglobin ( $\mathrm{Hb})$, hematocrit (PCV), white blood cell (WBC), platelet (Plt) evaluation were obtained from cephalic vein before the study and on the 5th and 12th days of study. Biochemical and haematological parameters were evaluated by autoanalyser (RocheHitachi P800, Japan) and blood cell counter (Coulter MAXM, USA), respectively. 


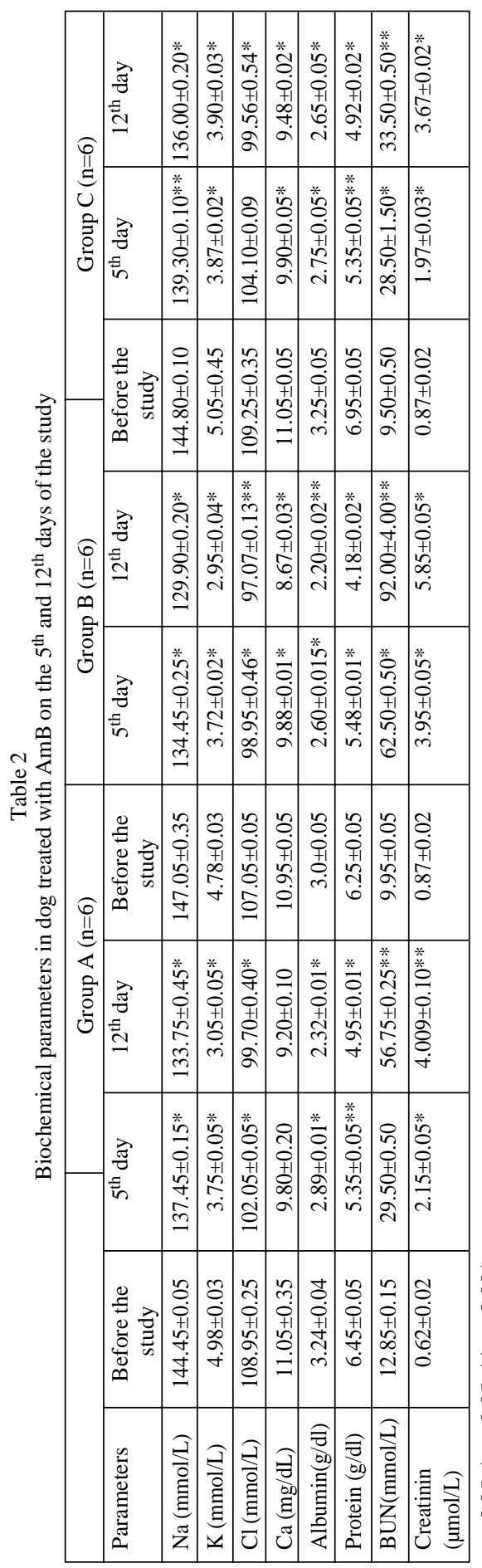

Urine samples collected by catheterization prior to initial dosing and on the $5^{\text {th }}$ and $12^{\text {th }}$ days of study for culture, specific gravity and gamma glutamyl transferase (GGT) values were evaluated by autoanalyser (RocheHitachi P800, Japan).

At the day after the final dose was administered two animals that were the worst for evaluated biochemical, haematological and histopathological parameters in each group were sacrificed by exsanguination under sodium pentobarbital anesthesia. Necropsy was performed on all sacrificed animals and the samples of kidneys were collected and fixed in 10\% phosphate buffered formalin. The kidney tissue sections were stained with haematoxylin and eosin (HE) and examined microscopically. Observed histopathological changes were graded for severity on a three degree (minimal, moderate and severe) base.

Statistical Analysis

Results are presented as means \pm S.E.M. The statistical significance of differences between groups (A, B and C) was evaluated using analysis of variance with repeated measures, and a paired Student's $t$-test.

Comparison of three groups with each other was performed by one-way analysis of variance (ANOVA). Groups with significant differences were compared with post-hoc Tukey test (Hayran and Ozdemir 1995).

\section{Results}

Before the experiment, the dogs were clinically healthy and their haematological and biochemical indices were within physiological ranges. Vomiting, diarrhea, anorexia, fever, phlebitis, depression, irritability, debility, weigth loss and tachycardia were observed beginning on the 3rd day of drug administration. These symptoms were less severe in Group A and C, whereas more pronounced in Group B.

In Group B, the difference of erythrocyte count and haemoglobin level was significantly lower when compared to the basal levels on the $12^{\text {th }}$ day $(p<0.05, p<0.001)$ (Table 1$)$.

In this group, whereas the difference in platelet count was not significant, haematocrit and WBC count decreased significantly both on the 5 th and the 12 th days $(p<0.05, p<0.001$, respectively). No significant alterations in these parameters were noted in Groups A and C (Table 1).

The biochemical parameters differed significantly $(p<0.05)$ on the 12th day, except $\mathrm{Ca}$ in group $\mathrm{A}$. All parameters except $\mathrm{Ca}$ in Group $\mathrm{A}$ and $\mathrm{Cl}$ in Group $\mathrm{C}$ were significantly different on the 5th day (Table 2). 
Table 3 and 4 show GGT values and urine specific gravity, respectively.

Histopathological changes in the kidney included vacuolar degeneration in tubules, nuclear loss in epithelial cells in the same proximal tubules, mineralized focuses in the cytoplasma, basophilic cylinder in collecting tubule lumens and vacuolar degeneration in the juxtaglomerular cells. Histopathological changes observed in Group B were more pronounced than in others groups.

\section{Discussion}

Nephrotoxic effects of some drugs used for treatment of infectious diseases in the dog have been known (Randal et al. 1996; Bekersky et al. 1999). AmB is associated with panoply of acute and chronic side effects, the most important of which is renal impairment with reduction in glomerular filtration rate (GFR) and irreversible renal tubular damage (Pyle 1981; Rubin et al. 1989; Sabra et al. 1990; Monteiro et al. 1993; Bekersky et al. 1999; Sabra et al. 2001). In many cases, the dose and duration of AmB use are limited by toxicity rather than by the clinical status of the patient (Maddux and Barriere 1980; Denning and Stevens 1990; Randal et al. 1996; Bekersky et al. 1999).

It was aimed to investigate the toxic effects of $\mathrm{AmB}$ in different doses and dilutions with $5 \%$ dextrose. In three groups, side effects of AmB such as vomiting, diarrhoea, anorexia, fever, phlebitis, irritability, weight loss and tachycardia were seen. All these side effects were similar to those of previously reported studies (Rubin et al. 1989; Randal et al. 1996; Bekersky et al. 1999; Eriksson et al. 2001). Vomiting may be attributable to the rapid infusion (4-5 min) of the drug which was not tolerated by dogs. Similar results had previously been reported by Randal (1996), Rubin et al. (1989), Bekersky et al. (1999) and Hoeprich et al. (1985).

Hyperaemia of the mucous membranes, haemorrhagic diarrhoea and tachycardia were observed in all dogs on the seventh day of the experiment. However, the observed symptoms were more pronounced in Groups B and C. These findings are in agreement with those of other investigators (Swanson and Cook 1977; Pyle 1981; Hoeprich et al. 1985). Weight loss in healthy dogs treated with AmB was an important finding (Rubin et al. 1989; B ekersky et al. 1999). In the present study, body weight loss was also seen in the dogs, and it possibly resulted from the drug-induced reduction in food intake. Similar results were reported by other researchers (Pyle 1981; Hoeprich et al. 1985; Rubin et al. 1989; Bekersky et al. 1999).

Table 3

Urine $\gamma$-GGT values before and on the $5^{\text {th }}$ and $12^{\text {th }}$ days of the study (IU/g).

\begin{tabular}{|l|c|c|c|}
\hline Groups & Before the study & $5^{\text {th }}$ day & $12^{\text {th }}$ day \\
\hline Group A & $93.42 \pm 8.12$ & $415.22 \pm 9.75^{* * *}$ & $465.20 \pm 11.21^{* * *}$ \\
\hline GroupB & $90.28 \pm 7.35$ & $440.65 \pm 18.64 * * *$ & $482.81 \pm 16.14^{* * *}$ \\
\hline Group C & $89.61 \pm 3.95$ & $408.17 \pm 4.23^{* * *}$ & $450.13 \pm 9.21^{* * *}$ \\
\hline
\end{tabular}

$-p>0.05, * p<0.05, * * p<0.001$

Significant changes in associated haematological parameters (RBC, Hb, Hct, WBC, PLT) were not found in groups $\mathrm{A}$ and $\mathrm{C}$, and there were significant decreases in haematological parameters only in Group B $(p<0.05)$. In clinical experience, anaemia is virtually a constant feature of treatment with AmB. Gastrointestinal bleeding, bone marrow suppression, erythropoiesis depression, and haemolysis are the principal mechanisms implicated in the production of anaemia (Swanson and Cook 1977). Juliano et al. (1987) showed that erythrocytes were much more susceptible to the membrane perturbing effects of AmB 
(S abra et al. 2001). AmB is highly haemolytic (Yu et al. 1998). These situations could be explained by the result of nephrotoxic effect of AmB. We have found similar findings in Group B, which was treated with $1 \mathrm{mg} \cdot \mathrm{kg}^{-1}$ in $50 \mathrm{ml} 5 \%$ dextrose as a rapid bolus (4-5 min).

Urine GGT levels increased in our study in all groups. This suggests that increased urine GGT level showed early renal damage (Uechi et al. 1994). Also Uechi et al. (1994) found very high levels of urine GGT values similar to our results.

There is a significant decrease in urinary osmolality due to probably the decrease in renal blood flow (Monteiro et al. 1993). However, these authors found that AmB produced a significant decrease in urine osmolality of dogs in which the drug was administered directly into the renal artery. In our study, decrease of urine specific gravity value was more pronounced in Group B which was treated with rapid bolus (4-5 min) than Group A and Group C (Table 3). In other two studies decreased urine specific gravity was also reported after administration AmB to dogs (Fielding et al. 1992; Bekersky et al. 1999).

We have found increased BUN and creatinin levels which were the most prominent on 12th day. Although serum electrolytes, total protein and albumin levels decreased through 12 days in all groups, there were no differences in any of these parameters (Table 2). These findings were in agreement with the literature (Bennett 1991; Bekersky et al. 1999; Eriksson et al. 2001).

Table 4

Urine spesific gravity before and on the 5 th and 12 th days of the study.

\begin{tabular}{|l|c|c|c|}
\hline Groups & Before the study & $5^{\text {th }}$ day & $12^{\text {th }}$ day \\
\hline Group A & $1.040 \pm 0.005$ & $1.028 \pm 0.006^{* * *}$ & $1.009 \pm 0.005^{* * *}$ \\
\hline Group B & $1.043 \pm 0.007$ & $1.020 \pm 0.004 * * *$ & $1.006 \pm 0.002^{* * *}$ \\
\hline Group C & $1.042 \pm 0.004$ & $1.032 \pm 0.002 * * *$ & $1.010+0.007 * * *$ \\
\hline
\end{tabular}

$-p>0.05, * p<0.05, * * p<0.001$

Electrolyte imbalance may be due to gastrointestinal side effects of the drug such as vomiting and diarrhoea. Additionally, hypocalemic effect of AmB is well-known (B ennett 1991; Eriksson et al. 2001). The most important toxic effects of AmB are renal dysfunction. Elevated BUN and creatinine are the most common findings of renal failure. In all of the three study groups, BUN and creatinine levels were increased, however slow infusion group was the least influenced although the highest dose of the drug was applied.

Renal histopathological changes were minimal in group $\mathrm{C}$, moderate in group A and severe in group B, because of dose-related effect of Amphotericin-B. The changes observed in this study, characterized by renal tubular nephrosis, nephrocalcinosis, tubular vacuolization and necrosis, were similar to those reported in dogs by Rubin et al. (1989) and Bekersky et al. (1999). Apparently, biochemical alterations recorded in our study are indications of these histopathological findings. It is, therefore, necessary to monitor biochemical parameters during AmB treatment in order to prevent some unwanted results. These results suggest that the toxicity of AmB for kidney could be decreased when administered in a long period and more diluted form.

\section{References}

ANDRIOLE, VT 2000: Current and future antifungal therapy: new targets for antifungal therapy. Int. Antimicrob Agents 16: 317-321

ARNING, M, SCHARF RE 1989: Prevention of amphotericin-B-induced nephrotoxicity by loading with sodium chloride: a report of 1291 days of treatment with amphotericin B without renal failure. Klin Wochenschr 67 : 1020-1028

BEKERSKY, I, BOSWELL, GW, HILES R, FIELDING RM, BUELL, D, WALSH, TJ 1999: Safety and toxicokinetics of intravenous liposomal Amphotericin B (AmBisome®) in beagle dogs. Pharmaceut Res 16: 1694-1701 
BEKERSKY, I, BOSWELL, GW, HILES, R, FIELDING RM, BUELL D, WALSH TJ 2000: Safety, toxicokinetics and tissue distribution of long-term intravenous liposomal Amphotericin B (AmBisome®): a 91-day study in rats. Pharmaceut Res 17: 1494-1502

BENNETT, JE 1991: Antimicrobial agents In Goodman and Oilman's (eds.) The pharmacological basis of therapeutics, Pergamon Press, pp. 1165-1181

BRAJTBURG, J, POWDERLY, WG, KOBAYASHI, GS, MEDOFF, G 1990: AmB: current understanding of mechanism of action. Antimicrob Agents Chemother 34: 183-188

CARLSON, MA, CONDON, RE 1994: Nephrotoxicity of amphotericin B. J Amer Coll Surg 179: 361-328

DENNING, DW, STEVENS, DA 1990: Antifungal and surgical treatment of invasive aspergillosis: Review of 2121 published cases. Rev Infect Dis 12: 1147-1201

ERIKSSON, U, SEIFERD, B, SCHAFFNER, A 2001: Comparison of effects of amphotericin B deoxycholate infused over 4 or 24 hours: randomised controlled trial. Brit Med J 322: 1-6

FIELDING, RM, SINGER, AW, WANG, LH, BABBAR, S, GUOR, LSS 1992: Relationship of pharmacokinetics and tissue distribution to reduced toxicity of colloidal amphotericin B in dogs. Antimicrob Agents Chemother 36: $299-307$

GALE, EF 1984: Mode of action and resistance mechanisms of polyene macrolides. In: S Omura (Ed), Macrolide, Antibiotics, Chemistry, Biology and Practice. Academic Press, London, pp. 425-455

GERKINS, JF, BRANCH, RA 1980: Influence of sodium status and furosemide on canine acute amphotericin B nephrotoxicity. J Pharmacol Exp Ther 214: 306-311

GERKINS, JF, HEIDEMANN, HT, JACKSON, EK, BRANCH, RA 1983: Effect of aminophylline on amphotericin B nephrotoxicity in the dog. J Pharmacol Exp Ther 244: 609-613

GOLD, W, STAUT, HA, PAGANO, JF, DONOVICK, R 1956: Amphotericins A and B, antifungal antibiotics produced by a Streptomycete. I. In vitro studies. In; Anibiotics Annual, 1955-1956, Medical Ancycplopedia Inc, New York, 579-586

GRAYBILL, J, CRAVEN, P 1983: Antifungal agents used in systemic mycoses. Drugs 25: 41-62

HAYRAN, M, OZDEMIR, 0 1995: Computer, Statistic and Medicine, Medikomat Press, Ankara.

HOEPRICH, P, D, HUSTON, C, WOLFE, BM 1985: Toxicity of amphotericins on chronic administration to Mongrel Dogs. Diagn Microbiol Infect Dis 3: 47-58

JOLY, V, DROMER, F, BARGE, J, YENI, P, SETA, N, MOLAS, G, CARBON, C 1989: Incorporation of amphotericin B (AMB) into liposomes alters AMB- induced acute nephrotoxicity in rabbits. J Pharmacol Exp Ther 251: 311-316

JULIANO, RL, GRANT, CW, BARBER, KR, KALP, MA 1987: Mechanism of the selectve toxicity of amphotericin B incorporated into liposoms. Mol Pharmacol 31: 1-11

LAMPEN, J 1969: Amphotericin B and other polyene antifungal antibiotics. Am J Clin Pathol 49: 143-150

MADDUX, MS, BARRIERE, SL 1980: A review of complications of amphotericin B therapy: Recommendations for prevention and management. Drug Intell Clin Pharm 14: 177-181

MONTEIRO, JL, SEGURO, AC, ROCHA, AS 1993: Acute nephrotoxicity caused by amphotericin B in the dog. Rev Hosp Clin Fac Med Sao Paulo 48: 54-59

NICHOLS, AJ, KOSTER, PF, BROOKS, DP, RUFFOLO, JR 1992: Effect of fenoldopam on the acute and subacute nephrotoxicity produced by amphotericin B in the dog. J Pharmacol Exp Ther 260: 269-274

OLIVA, G, GRADONI, L, CIARAMELLA, P, DE LUNA, R, CORTESE, L, ORSINI, S, DAVIDSON, RN, PERSECHINO, A 1995: Activity of liposomal amphotericin B (AmBisome) in dogs naturally infected with Leishmania infantum. J Antimicrob Chemother 36: 1013-1019

PERFECT, JR, PICKARD, WW, HUNT, DL, PALMER, B, SCHELL, WA 1991: The use of amphotericin B in nosocomial fungal infection. Rev Infect Dis 13: 474-479

PYLE RL 1981: Clinical pharmacology of amphotericin B, JAVMA 179: 83-84

RANDALL, SR, ADAMS, LG, WHITE, MR, DENICHOLA, DB 1996: Nephrotoxicity of amphotericin B administered to dogs in a fat emulsion versus five percent dextrose solution, AJVR 57: 1054-1058

RUBIN, SI, KRAWIEC, DR, GELBERG, H, SHANKS, RD 1989: Nephrotoxicity of amphotericin B in dogs: a comparison of two methods of administration. Can J Vet Res 53: 23-28

SABRA, R, TAKAHASHI, K, BRANCH, R, BADR, AKF 1990: Mechanisms of amphotericin B-induced reduction in glomerular filtration rate: a micropuncture study. J Pharmacol Exp Therap 1\% 2097-2107

SABRA, R, ZEINOUN, LN, SHARAF, H, GHALI, R, BESHARA, G, SERHAL, H 2001: Role of humoral mediators in, and influence of a Liposomal formulation on, acute Amphotericin B nephrotoxicity. Pharm and Toxicol 88: $168-175$

SWANSON, M, COOK, R 1977: Drugs, Chemicals, and Blood Dyscrasias. Hamilton, Illinois: Drug Intelligence Publications Inc, pp. 61-66

UECHI, M, TERUI, H, NAKAYAMA, T, MISHINA, M, WAKAO, Y, TAKAHASHI, M 1994: Circadian variation of urinary enzymes in the dog. J Vet Med Sci 56: 849-854

YARDLEY, V,CROFT, SL 2000: A comparison of the activities of three amphotericin B lipid formulations against experimental visceral and cutaneous leishmaniasis. Int J Antimicrob Agents 13: 243-248

YU, BG, OKANO, T, KATAOKA, K, KWON, G 1998: Polymeric micelles for drug delivery: solubilization and haemolytic activity of amphotericin B J Controlled Release 53: 131-136 